\title{
The Biology of Retinopathy of Prematurity
}

\section{Citation}

Smith, Lois E., Anna-Lena Hard, and Ann Hellström. 2013. The Biology of Retinopathy of Prematurity. Clinics in Perinatology 40, no. 2: 201-214. doi:10.1016/j.clp.2013.02.002.

\section{Published Version}

doi:10.1016/j.clp.2013.02.002

\section{Permanent link}

http://nrs.harvard.edu/urn-3:HUL.InstRepos:33776192

\section{Terms of Use}

This article was downloaded from Harvard University's DASH repository, and is made available under the terms and conditions applicable to Other Posted Material, as set forth at http:// nrs.harvard.edu/urn-3:HUL.InstRepos:dash.current.terms-of-use\#LAA

\section{Share Your Story}

The Harvard community has made this article openly available.

Please share how this access benefits you. Submit a story.

\section{Accessibility}




\title{
The Biology of Retinopathy of Prematurity: How Knowledge of Pathogenesis Guides Treatment
}

\author{
Lois E. Smith, M.D., Ph.D. ${ }^{1,{ }^{*}}$, Anna-Lena Hard, M.D., Ph.D. ${ }^{2}$, and Ann Hellström, M.D., Ph.D. \\ $2,{ }^{*}$ \\ ${ }^{1}$ Department of Ophthalmology, Children's Hospital Boston, Harvard Medical School, Boston, MA \\ 2Section of Pediatric Ophthalmology, The Queen Silvia Children's Hospital, The Sahlgrenska \\ Academy at University of Gothenburg, S-416 85 Göteborg, Sweden
}

\section{Keywords}

oxygen; IGF-I; omega-3 polyunsaturated fatty acids; postnatal weight gain; erythropoietin

\section{Introduction}

ROP occurs because the retina of a preterm infant at birth is incompletely vascularized and if the postnatal environment does not match the in utero environment that supported retinal development, the vessels and neural retina will not grow normally. Risk factors determined from many clinical studies and animal studies fall into two categories ${ }^{1}$ :

1. Prenatal factors

Those that reflect the degree of incomplete neurovascular development at birth indicating the susceptibility of the retina to harm

a. Gestational age at birth

b. Birth weight

2. Postnatal factors

Factors after preterm birth that differ from the in utero environment of the third trimester and therefore do not match the extra-uterine needs of the baby and prevent resumption of normal retinal neurovascular growth after birth:

a. exposure to oxygen which is higher and/or more variable than that found during gestation that alters the oxygen-regulated growth factors

b. loss of the maternal-fetal interaction resulting in:

(C) 2013 Elsevier Inc. All rights reserved.

Corresponding Authors: Lois Smith, M.D., Ph.D. Children's Hospital Boston, Department of Ophthalmology, Fegan 4, 300

Longwood Avenue, Boston, MA 02115, Lois.Smith@ childrens.harvard.edu. Ann Hellstrom, Section of Pediatric Ophthalmology, The Queen Silvia Children's Hospital, The Sahlgrenska Academy at University of Gothenburg, S-416 85 Göteborg, Sweden.

${ }^{3}$ These authors contributed equally to the work.

* equal contribution

Publisher's Disclaimer: This is a PDF file of an unedited manuscript that has been accepted for publication. As a service to our customers we are providing this early version of the manuscript. The manuscript will undergo copyediting, typesetting, and review of the resulting proof before it is published in its final citable form. Please note that during the production process errors may be discovered which could affect the content, and all legal disclaimers that apply to the journal pertain. 
Increased metabolic demands ${ }^{2}$ in the face of loss of nutrition (including essential fatty acids)

Decreased IGF-I levels and loss of other factors resulting in poor postnatal growth and weight gain ${ }^{3-5}$

Much of our understanding of retinopathy of prematurity (ROP) has come from observations in the clinic, followed by animal studies to determine pathogenesis, which then are played out in clinical intervention studies resulting in changes in clinical practice. Optimally this cycle continues to refine patient care.

ROP was first described as "retrolental fibroplasia" by Terry in $1942 .{ }^{6}$ In 1952, Patz and coworkers demonstrated in a clinical study the association between oxygen and $\mathrm{ROP}^{7}$. In an experimental kitten model ${ }^{8}$, Ashton then established the concepts of oxygen toxicity and vessel loss (phase I) followed by hypoxia-mediated vasoproliferation (phase II). Thus these studies characterized ROP as a two-phased disease of preterm infants with initial cessation of vessel growth caused by exposure to high levels of oxygen and loss of formed vessels followed by pathological neovascularization of the retina. As a result of these findings, oxygen use was severely curtailed for a time and although ROP incidence decreased, many infants died as a result. ${ }^{9}$

The balance between sufficient supplemental oxygen to prevent death versus minimal oxygen to prevent ROP has still not been settled for premature infants at different gestational and postmenstrual ages despite a large number of clinical studies addressing aspects of the question. ${ }^{10}$ The effect of supplemental oxygen use in phase I and phase II of ROP in these studies suggests that high oxygen saturation levels in phase I is a significant risk factor and oxygen supplementation in phase II may reduce ROP risk slightly but may also increase lung disease. ${ }^{11,12}$ These studies though hinting at the best use are not yet definitive and we await a clinical study that will better inform optimal use of oxygen at different GA, different PMA.

ROP persists as a major cause of blindness in children despite better oxygen monitoring ${ }^{13,14}$ as neonatal practices improve and infants at earlier gestational ages survive, with extreme retinal immaturity at birth. ${ }^{15}$ The immature retina is susceptible not only to oxygen levels higher than those in utero but also to variable oxygen tensions and to lack of growth factors and nutrients normally provided in utero, all of which cause vessel loss and cessation of vessel growth.

Studies using animal models of oxygen-induced retinopathy (OIR) have rationalized current ROP treatment and also identified new therapeutic interventions, which may be used to prevent or predict ROP.

\section{Pathogenesis of ROP}

What contributes to the susceptibility of the immature retina of the preterm infant and what are the differences between the in utero and extra uterine environment that contribute to the cessation of postnatal retinal vascular growth?

\section{Normal retinal development}

To understand pathology, we must understand normal retinal vascular development. In the human, retinal vascularization occurs predominantly in the second and third trimesters in utero and reaches maturity at 36 to 40 weeks postmenstrual age (PMA) through vasculogenesis and angiogenesis. $8,16,17$ The scaffold of the future retinal vasculature is laid 
down by vascular precursor cells (vasculogenesis) from 12 weeks to $~ 21$ weeks gestational age, before viable preterm birth. ${ }^{18,19}$

Angiogenesis commences at approximately 17 weeks PMA and expands on the vascular scaffold starting at the optic nerve radiating outward. New vessels bud from existing ones until vascular development is complete, just prior to full term birth. ${ }^{19}$ Angiogenesis is stimulated by the "physiologic hypoxia" of the developing retina described in animal studies $^{20}$. That is, when the metabolic demands of the maturing neural retina outpace the oxygen supplied by the underlying choroid, and the encroaching retinal vascular network, vasoactive factors (particularly VEGF) are secreted by the avascular retina, which stimulates new vessel formation. $8,20-22$

\section{Phase I ROP: interruption of development with hyperoxia and under- nutrition}

Just as the formation of the retinal vasculature responds to "physiological" hypoxia with developmental progression, it is sensitive to non-physiological hyperoxia, which is often encountered after preterm birth. The oxygen saturation of the fetus in the uterine environment is $\sim 60-70 \%$. Thus preterm birth into room air often causes an increase in oxygen saturation, which is further exacerbated by supplemental oxygen. ${ }^{23}$ Hyperoxia suppresses "physiologic hypoxia" causing down-regulation of hypoxia-inducible factor (Hif) regulated growth factors resulting in disruption of normal vascular development ${ }^{8,24}$. Notably, the loss of factors from the maternal fetal interface, (e.g. nutrition and other mediators of postnatal growth) also contributes to low serum IGF-I and disruption in vessel growth and phase I of ROP. ${ }^{24}$

\section{Phase II ROP}

In severely affected infants, a proliferative phase (Phase II), follows the vessel loss of Phase I. ${ }^{8}$ The degree of hypoxia and extent of avascular retina induced by phase I ROP determines the degree of hypoxia-derived proliferative factors, which determine the degree of phase II ROP. Phase II begins to develop after more than 32 postmenstrual weeks but can have a wide range of onset. ${ }^{25,} 26$ Even infants born at 32 weeks GA are susceptible to vessel loss when exposed to very high oxygen saturations after birth resulting in severe proliferative ROP. ${ }^{27}$

The transition to phase II occurs when the attenuated vasculature cannot supply enough oxygen (and nutrients) to the developing retina, leading to increased expression of hypoxiainduced factors. These growth factors then stimulate aberrant vessel formation at the junction between vascularized and avascular retina. ${ }^{24}$ Paradoxically these pathological vessels do not reperfuse the avascular retina but stop at the avascular junction. If the retina receives ample oxygenation, then these pathologic vessels may regress. If the demands of the retina continue to outstrip the oxygen and nutrient supply, then exuberant neovascularization may continue. ${ }^{8}$ Neovascular proliferation may cause retinal folds, macular dragging, and cicatricial changes sometimes ultimately causing retinal detachment and blindness. (Figure 1)

\section{Molecular mechanism of oxygen influences on phase I and II of ROP}

\section{Animal Models of Oxygen-induced Retinopathy}

Following the first description of the disease in the earliest studies ${ }^{7,28}$ animal studies have uncovered the molecular mediators of the effects of hyperoxia and hypoxia on retinal vascular development. ${ }^{2329,30}$ Animal models of oxygen-induced retinopathy (OIR) have 
been developed in the neonatal kitten, dog, rat, and mouse. The mouse OIR model is currently the most commonly used model as it is reproducible, can be reliably quantified and can be manipulated genetically. ${ }^{3024}$ (Figure 2)

\section{Hypoxia induced factors and ROP: Vascular endothelial growth factor (VEGF)}

The role of the endothelial cell mitogen and vascular permeability factor VEGF which plays a critical role in both phase I and phase II ROP was first described in animal studies of OIR. ${ }^{21,22,30-37}$

\section{Phase I: VEGF is suppressed by hyperoxia, suppressing normal vessel growth}

During retinal development, the wave front of "physiologic hypoxia" resulting from increasing metabolic demand of developing neurons, induces a wave of VEGF, which results in extension of forming vessels The VEGF wave is suppressed with exposure to hyperoxia, causing cessation of normal vascular development seen in phase I of ROP. ${ }^{20,29-32,36}$

In mouse OIR, after 6 hours exposure to 75\% oxygen, both VEGF mRNA and protein levels are suppressed with loss of microvessels and cessation of new vessel formation. ${ }^{22}$ This vessel loss can be inhibited by intravitreal injection of VEGF or the VEGFR-1 specific ligand placental growth factor-1 (PlGF-1). ${ }^{22}, 33$

\section{Clinical Implications of VEGF and Phase I of ROP}

This demonstrates that oxygen suppression of VEGF during phase I of ROP is a major contributor to vessel loss. These animal studies rationalize the judicious use of oxygen during the early postnatal period where there is incomplete retinal vascularization to minimize VEGF suppression to minimize vessel loss.

\section{Phase II}

\section{VEGF is over-expressed in phase II causing neovascularization}

In the mouse OIR model, with return to room air, the now vaso-compromised retina becomes hypoxic which induces VEGF mRNA and protein expression ${ }^{21}$, which are directly linked to aberrant neovascularization. ${ }^{21,22,34,35}$

\section{Clinical implications of VEGF in phase II of retinopathy}

Studies in the OIR model again help us understand the pathogenesis of phase II, showing that neovascularization can be inhibited by targeting VEGF in phase II with intravitreal injections of anti-VEGF compounds including antisense oligodeoxynucleotides, antibodies against VEGF or small interfering RNA (siRNA). ${ }^{34,35,38}$ These animal studies are the basis of the clinical use of intravitreal injections of anti-VEGF drugs for retinopathy and for age related macular degeneration (AMD).

Several VEGF inhibitors have been FDA approved for intraocular injection to treat neovascular AMD and diabetic macular edema including an antibody fragment Lucentis@ (ranibizumab). The full anti-VEGF antibody, Avastin $\odot$ (bevacizumab), is used off label for treatment of these diseases. Although Avastin is neither approved for use in eyes, nor in infants, and intravitreal Avastin injections suppress serum VEGF for weeks in preterm infants ${ }^{39}$, reports of its use is steadily increasing. There are several case reports of the use of 
these agents with moderate success in severe cases of ROP which have been refractory to laser treatment ${ }^{40}$ or in patients with vitreal bleeding or opaque media unsuitable for laser treatment. ${ }^{41}$ In these reports, there was regression of ROP with no adverse systemic or intraocular outcomes reported.

Mintz-Hittner and Kuffel studied the effects of bevacizumab treatment of moderate and severe ROP in eyes that had not previously undergone laser ablation. ${ }^{42}$ Twenty-two eyes received intravitreal injection of bevacizumab. The mean follow up was 48.5 weeks. After a single injection, treatment was considered successful in all eyes. Adverse systemic or intraocular outcomes were not examined. ${ }^{42}$

\section{New anti-VEGF studies needed to optimize clinical care}

Just as the optimal balance point must be found with supplemental oxygen- enough to prevent brain dysfunction and death but not so much that vascular growth in the eye is suppressed, the balance between sufficient and insufficient VEGF is unknown. In phase I ROP, hyperoxia downregulates VEGF thereby pruning the vascular tree since fewer vessels are needed with high oxygen. However in the hypoxic phase II there is again a need for more vessels and VEGF is dramatically up-regulated, contributing to aberrant vessel growth. ${ }^{43}$

A large randomized controlled clinical trial is needed to determine the appropriate antiVEGF agent, the appropriate dosing and timing of treatment as well as the long-term ocular and systemic outcomes. While current limited studies appear promising, careful attention must be paid to assess potential long term ophthalmic and neurological and other systemic consequences of VEGF inhibitor use in the developing neonate since rapid VEGF-dependent development of vital organs such as brain, lungs and kidneys normally takes place during the third trimester. Anti-VEGF treatment could compromise this development.

\section{VEGF and Laser Ablation Treatment of ROP}

Over the last few decades, treatment with retinal ablation (cryotherapy and laser therapy) during phase II of ROP, have decreased severe vision loss. ${ }^{44-46}$ The mechanism of the ablative treatment has been rationalized in terms of animal studies showing that hypoxic retina (that is destroyed by these interventions) is the source of angiogenic factor release that causes vasoproliferation. This was confirmed in an autopsy study showing that laser photocoagulation reduced VEGF expression in ROP treated retina compared to an untreated fellow eye. ${ }^{47,48}$

\section{Erythropoietin (Epo)}

Erythropoietin (Epo) is a second hypoxia-induced factor, independent of VEGF, which has been shown in in vitro and in vivo in studies in the OIR mouse to be important in normal retinal angiogenesis in phase I and in neovascularization in phase II of oxygen-induced retinopathy. ${ }^{24}$ In vitro Epo is as potent as VEGF in inducing angiogenesis. ${ }^{49,}$ 505152, 53 Epo is secreted locally in the retina as well as by the fetal liver and adult kidney to induce erythopoiesis in the bone marrow, apoptosis in neurons and vascular cells, and angiogenesis. ${ }^{37}$

\section{Clinical implications of Epo contributing to ROP}

During phase II ROP, Epo levels rise concomitant with neovascularization. There is at present no anti-Epo drug to inhibit proliferative retinopathy, although the effect of Epo inhibition in phase II is as great as that of inhibiting VEGF, and development of an anti-Epo drug could be beneficial. ${ }^{54,55}$ 
In some NICUs, anemia in premature infants is treated with the administration of recombinant human Epo (rhEPO). ${ }^{24,56}$ In a recent retrospective study of premature babies, rhEPO treatment was found to be a risk factor for the development of threshold ROP requiring photoablative laser. ${ }^{56} \mathrm{~A}$ Cochrane review suggested that in humans, EPO use was associated with an increased risk of ROP (any grade) with a similar trend for ROP stage $\geq 3$ although infants were not classified according to PMA. ${ }^{57}$

\section{Factors lacking after preterm birth and ROP}

\section{Insulin-like growth factor-1 (IGF-I)}

Animal studies have been instrumental in understanding the influence of postnatal factors affecting vascular growth on the development of ROP.58 Specifically IGF-I has been shown to be critical in both phase I and phase II of retinopathy in the OIR model in the mouse. ${ }^{59,60}$ IGF-I is a polypeptide that promotes human fetal growth throughout gestation but particularly in the third trimester, IGF-I levels increase both in the maternal serum and in the fetus. ${ }^{61}$ Serum IGF-I levels correlate with weight gain throughout childhood. ${ }^{62}$

In premature infants, the sudden loss of the maternal fetal interaction (e.g. loss of nutrients in the setting of increased metabolic demand, loss of placental IGF-1, and other regulating factors) contributes to the dramatic reduction in serum IGF-I after preterm birth. IGF-I synthesis in the liver of the fetus/preterm infant is dependent on nutrient supply and level of maturity. ${ }^{63}$

Low serum IGF-I has been correlated with decreased fetal growth and development. ${ }^{24,64}$ Comparison of the longitudinal serum levels of IGF-I between full term and preterm babies, show that both groups have a decrease in circulating IGF-I levels after birth. However, full term infants experience a postnatal surge of IGF-I between day 1 and day 15 of life not seen in preterm infants. ${ }^{65}$ The immaturity of the very preterm infant in combination with poorly known nutritional needs precludes proper accretion of nutrients, which will likely reduce IGF-I secretion to slow maturation.

Studies in animal models have shown the importance of low IGF-I to the development of ROP. ${ }^{24,59,60}$ Both growth hormone and its mediator for growth, IGF-I, are important in angiogenesis. Genetic defects in the growth hormone/IGF-I axis result in subnormal vascularization of the retina. ${ }^{66}$ In IGF-I knockout mice, retinal vessel growth is suppressed although VEGF levels are comparable in wild type and IGF-I-/- mice suggesting that VEGF is necessary but not sufficient to promote angiogenesis. ${ }^{60}$

IGF-I is necessary for maximum VEGF signaling of the Akt and MAP kinase pathway critical for endothelial cell survival and proliferation. This suggests that a minimal level of IGF-I is required for vascular growth, rationalizing the poor vascular growth seen in phase I in premature infants with ROP. This is supported by the increased growth and decreased ROP after early IGF-I treatment reported in starving mouse pups subjected to OIR. ${ }^{67}$

IGF-I is also important in phase II ROP. There is suppressed neovascularization in the OIR growth hormone receptor (and IGF-I) deficient mouse, which is restored through exogenous administration of IGF-I or an IGF-I receptor antagonist. Again, reduction in IGF-I results in a down-regulation of VEGF-mediated MAPK and Akt pathway activation rather than directly affecting VEGF levels. ${ }^{59,} 68,69$

These animal studies have uncovered the links between IGF-I and VEGF where IGF-I behaves as a permissive agent in VEGF-mediated angiogenesis. In the premature infant, vessel growth is suppressed with the drop in circulating IGF-I levels. As the infant grows, 
the body slowly produces endogenous IGF-I; once a threshold is reached, VEGF-induced neovascularization may ensue.

\section{Clinical Implications: Postnatal IGF-1 levels and postnatal growth predict ROP}

These animal studies have also suggested the importance of using either low serum IGF-I or the linked parameter of poor postnatal weight gain as a predictor for those infants at highest risk for ROP. ${ }^{3-5,70-74}$ They also suggest that IGF-I replacement might prevent ROP and related complications of premature birth by fostering postnatal growth. ${ }^{75}$

Based on these studies, which gave rise to an understanding of the relationship between IGF-I, postnatal growth and angiogenesis, a new diagnostic algorithm "Weight IGF-I Neonatal ROP" (WINROP ${ }^{\mathrm{TM}}$ ) was developed in 2006. WINROP utilizes rate of postnatal weight gain as a reflection of IGF-1 or uses weight gain and IGF-I levels together as highly predictive markers for those infants at increased risk for development of proliferative ROP. The WINROP algorithm predicts which infants will or will not develop ROP by assessing deviations in the rate of increase in weight and serum IGF-I of infants who later developed severe ROP from those who developed no or mild ROP using online statistical surveillance (www.winrop.com). In the initial cohort of 79 preterm infants followed longitudinally with weekly postnatal weight and serum IGF-I measurements, all patients who developed proliferative ROP were identified at least 5 weeks prior to treatment for severe ROP. ${ }^{3}$

After the initial validations using postnatal changes in both IGF-I and weight gain ${ }^{10}$, this algorithm has been used since 2009 with postnatal weight gain alone with validation in $>10,000$ infants worldwide. The sensitivity $(90 \%-100 \%)$ as well as the specificity $(38.7 \%-$ $81.7 \%$ ) has varied in different international preterm populations in Sweden, Switzerland, Canada, the US, Brazil, and Mexico ${ }^{4,70-74}$. This is considered to be due to the different composition and characteristics of the preterm population in different countries. This tool also helped to determine early which infants are at low risk thus reducing the number of eye examinations in that population while concentrating observation on those infants at high risk. $^{4}$

With the WINROP algorithm, it has become clear that although treatment may not be warranted until many weeks postnatally, the initial changes in weight gain in the first several weeks of life significantly affects ROP development. ${ }^{4}$ Several other algorithms have since been developed that confirm that postnatal weight gain can be used to predict later development of $\operatorname{ROP}^{76,77}$.

\section{Omega-3 Long Chain Polyunsaturated Fatty Acids (LCPUFAs) in OIR in Mice}

Through mouse OIR studies, the important role of the exogenously (usually diet) derived omega-3 LCPUFA docosahexaenoic acid, DHA in preventing ROP has been elucidated. ${ }^{24,7879}$ In the third trimester there is a massive transfer of essential fatty acids from mother to fetus, which is lost after preterm birth.

The principal retinal omega-3 LCPUFA is DHA and the main retinal omega-6 LCPUFA is arachidonic acid (AA). Animal studies have shown that the balance of omega- 3 to omega- 6 LCPUFA in the retina affects vascular and neuronal survival. ${ }^{24,78}$ In extremely preterm infants who are given lipids mainly from intravenous supplementation which does not contain omega-3 LCPUFAs there is a deficit of this essential fatty acid, which has been shown to be critical in preventing retinopathy in animal models.

In phase II ROP, there is a large decrease in the extent of vessel loss (and decreased neovascularization) in pups raised on an isocaloric diet with $2 \%$ of total fatty acids from omega-3 PUFAs in contrast to a diet enriched in omega-6 PUFAs. This suppression of 
proliferative ROP occurs through improved regrowth of vessels after vessel loss as well as direct suppression of neovascularization in part through suppression of inflammation. ${ }^{78}$ Supplementation with the downstream metabolites of omega-3 PUFAs, including neuroprotectin D1, resolvins D1 and E1, and 4HDHA also prevented neovascularization. ${ }^{78,79}$

\section{Clinical Implication of ROP and DHA}

The anti-neovascular effects of the omega-3 PUFA DHA supplementation are as strong as anti-VEGF therapy in the mouse OIR model suggesting supplementing oral or parenteral intake of DHA is another potential target to control ROP. ${ }^{24}$

\section{Summary}

ROP is a clinically multifactorial process with potentially devastating effects on vision in premature infants. Prevention includes improved oxygen control with avoidance of fluctuations and provision of sufficient nutrition as early as possible. New preventative strategies including IGF-I replacement and DHA supplementation and possible suppression of the hypoxia related factor, VEGF, have been identified through insights into the molecular pathogenesis of ROP in animal studies. Any strategy which seeks to modulate the key elements in retinal angiogenesis, must consider their phase-specific effects. Further, the WINROP algorithm and others based on our understanding from mouse studies of IGF-I and the importance of the related postnatal growth in in premature infants at risk for ROP provides a novel method of identifying early those infants at highest risk for ROP, potentially targeting therapy and resources more effectively towards these babies.

\section{Acknowledgments}

AH received support from the Swedish Medical Research Council (grant \# 2011-2432), Government grants (\#ALFGB-137491), VINNOVA (grant \# 2009-00221). LEHS received support from Research to Prevent Blindness Sr. Investigator Award, NEI EY017017, NEI EY022275, NIH P01 HD18655, and the Lowy Medical Foundation

\section{References}

1. Wikstrand MH, Hard AL, Niklasson A, Smith L, Lofqvist C, Hellstrom A. Maternal and neonatal factors associated with poor early weight gain and later retinopathy of prematurity. Acta Paediatr. 2011

2. Singer D, Muhlfeld C. Perinatal adaptation in mammals: the impact of metabolic rate. Comp Biochem Physiol A Mol Integr Physiol. 2007; 148(4):780-4. [PubMed: 17561425]

3. Lofqvist C, Andersson E, Sigurdsson J, et al. Longitudinal postnatal weight and insulin-like growth factor I measurements in the prediction of retinopathy of prematurity. Arch Ophthalmol. 2006; 124(12):1711-8. [PubMed: 17159030]

4. Hellstrom A, Hard AL, Engstrom E, et al. Early weight gain predicts retinopathy in preterm infants: new, simple, efficient approach to screening. Pediatrics. 2009; 123(4):e638-45. [PubMed: 19289449]

5. Lofqvist C, Hansen-Pupp I, Andersson E, et al. Validation of a new retinopathy of prematurity screening method monitoring longitudinal postnatal weight and insulinlike growth factor I. Arch Ophthalmol. 2009; 127(5):622-7. [PubMed: 19433710]

6. Terry TL. Extreme prematurity and fibroblastic overgrowth of persistent vascular sheath behind each crystalline lens. Am J Ophthalmol. 1942; 25:203-204.

7. Patz A, Hoeck LE, De La Cruz E. Studies on the effect of high oxygen administration in retrolental fibroplasia. I. Nursery observations. Am J Ophthalmol. 1952; 35(9):1248-53. [PubMed: 12976495]

8. Ashton N, Ward B, Serpell G. Effect of oxygen on developing retinal vessels with particular reference to the problem of retrolental fibroplasia. Br J Ophthalmol. 1954; 38(7):397-432.

[PubMed: 13172417] 
9. Bolton DP, Cross KW. Further observations on cost of preventing retrolental fibroplasia. Lancet. 1974; 1(7855):445-8. [PubMed: 4131442]

10. Stenson B, Brocklehurst P, Tarnow-Mordi W. Increased 36-week survival with high oxygen saturation target in extremely preterm infants. N Engl J Med. 2011; 364(17):1680-2. [PubMed: 21524227]

11. Supplemental Therapeutic Oxygen for Prethreshold Retinopathy Of Prematurity (STOP-ROP), a randomized, controlled trial. I: primary outcomes. Pediatrics. 2000; 105(2):295-310. [PubMed: 10654946]

12. Chen ML, Guo L, Smith LE, Dammann CE, Dammann O. High or low oxygen saturation and severe retinopathy of prematurity: a meta-analysis. Pediatrics. 2010; 125(6):e1483-92. [PubMed: 20498174]

13. Gilbert C, Muhit M. Twenty years of childhood blindness: what have we learnt? Community eye health/International Centre for Eye Health. 2008; 21(67):46-7. [PubMed: 19030129]

14. Gilbert C, Foster A. Childhood blindness in the context of VISION 2020--the right to sight. Bulletin of the World Health Organization. 2001; 79(3):227-32. [PubMed: 11285667]

15. Gilbert C, Fielder A, Gordillo L, et al. Characteristics of infants with severe retinopathy of prematurity in countries with low, moderate, and high levels of development: implications for screening programs. Pediatrics. 2005; 115(5):e518-25. [PubMed: 15805336]

16. Roth AM. Retinal vascular development in premature infants. Am J Ophthalmol. 1977; 84 (5): 636-40. [PubMed: 563174]

17. Michaelson IC. The mode of development of the vascular system of the retina, with some observations on its significance for certain retinal diseases. Trans Ophthalmol Soc U K;. 68:137180.

18. Chan-Ling T, McLeod DS, Hughes S, et al. Astrocyte-endothelial cell relationships during human retinal vascular development. Invest Ophthalmol Vis Sci. 2004; 45(6):2020-32. [PubMed: 15161871]

19. Hughes S, Yang H, Chan-Ling T. Vascularization of the human fetal retina: roles of vasculogenesis and angiogenesis. Invest Ophthalmol Vis Sci. 2000; 41(5):1217-28. [PubMed: 10752963]

20. Chan-Ling T, Gock B, Stone J. The effect of oxygen on vasoformative cell division. Evidence that 'physiological hypoxia' is the stimulus for normal retinal vasculogenesis. Invest Ophthalmol Vis Sci. 1995; 36(7):1201-14. [PubMed: 7775098]

21. Pierce EA, Avery RL, Foley ED, Aiello LP, Smith LE. Vascular endothelial growth factor/vascular permeability factor expression in a mouse model of retinal neovascularization. Proc Natl Acad Sci U S A. 1995; 92(3):905-9. [PubMed: 7846076]

22. Pierce EA, Foley ED, Smith LE. Regulation of vascular endothelial growth factor by oxygen in a model of retinopathy of prematurity. Arch Ophthalmol. 1996; 114(10):1219-28. [PubMed: 8859081]

23. Madan A, Penn JS. Animal models of oxygen-induced retinopathy. Frontiers in bioscience: a journal and virtual library. 2003; 8:d1030-43. [PubMed: 12700061]

24. Smith LE. Through the eyes of a child: understanding retinopathy through ROP the Friedenwald lecture. Invest Ophthalmol Vis Sci. 2008; 49(12):5177-82. [PubMed: 18708611]

25. Good WV, Hardy RJ, Dobson V, et al. The incidence and course of retinopathy of prematurity: findings from the early treatment for retinopathy of prematurity study. Pediatrics. 2005; 116(1): 15-23. [PubMed: 15995025]

26. Austeng D, Kallen KB, Hellstrom A, Tornqvist K, Holmstrom GE. Natural history of retinopathy of prematurity in infants born before 27 weeks' gestation in Sweden. Arch Ophthalmol. 2010; 128(10):1289-94. [PubMed: 20937998]

27. Shah PK, Narendran V, Kalpana N. Aggressive posterior retinopathy of prematurity in large preterm babies in South India. Arch Dis Child Fetal Neonatal Ed. 2012; 97(5):F371-5. [PubMed: 22611114]

28. Campbell K. Intensive oxygen therapy as a possible cause of retrolental fibroplasia; a clinical approach. The Medical journal of Australia. 1951; 2(2):48-50. [PubMed: 14874698] 
29. Chen J, Smith LE. Retinopathy of prematurity. Angiogenesis. 2007; 10(2):133-40. [PubMed: 17332988]

30. Smith LE, Wesolowski E, McLellan A, et al. Oxygen-induced retinopathy in the mouse. Invest Ophthalmol Vis Sci. 1994; 35(1):101-11. [PubMed: 7507904]

31. Shweiki D, Itin A, Soffer D, Keshet E. Vascular endothelial growth factor induced by hypoxia may mediate hypoxia-initiated angiogenesis. Nature. 1992; 359(6398):843-5. [PubMed: 1279431]

32. Leung DW, Cachianes G, Kuang WJ, Goeddel DV, Ferrara N. Vascular endothelial growth factor is a secreted angiogenic mitogen. Science. 1989; 246(4935):1306-9. [PubMed: 2479986]

33. Shih SC, Ju M, Liu N, Smith LE. Selective stimulation of VEGFR-1 prevents oxygen-induced retinal vascular degeneration in retinopathy of prematurity. J Clin Invest. 2003; 112(1):50-7. [PubMed: 12840058]

34. Aiello LP, Pierce EA, Foley ED, et al. Suppression of retinal neovascularization in vivo by inhibition of vascular endothelial growth factor (VEGF) using soluble VEGF-receptor chimeric proteins. Proc Natl Acad Sci U S A. 1995; 92(23):10457-61. [PubMed: 7479819]

35. Robinson GS, Pierce EA, Rook SL, Foley E, Webb R, Smith LE. Oligodeoxynucleotides inhibit retinal neovascularization in a murine model of proliferative retinopathy. Proc Natl Acad Sci U S A. 1996; 93(10):4851-6. [PubMed: 8643492]

36. Stone J, Itin A, Alon T, et al. Development of retinal vasculature is mediated by hypoxia-induced vascular endothelial growth factor (VEGF) expression by neuroglia. J Neurosci. 1995; 15 (7 Pt 1): 4738-47. [PubMed: 7623107]

37. Stone J, Chan-Ling T, Pe'er J, Itin A, Gnessin H, Keshet E. Roles of vascular endothelial growth factor and astrocyte degeneration in the genesis of retinopathy of prematurity. Invest Ophthalmol Vis Sci. 1996; 37(2):290-9. [PubMed: 8603833]

38. Jiang J, Xia XB, Xu HZ, et al. Inhibition of retinal neovascularization by gene transfer of small interfering RNA targeting HIF-1alpha and VEGF. Journal of cellular physiology. 2009; 218(1): 66-74. [PubMed: 18767037]

39. Sato T, Wada K, Arahori H, et al. Serum Concentrations of Bevacizumab (Avastin) and Vascular Endothelial Growth Factor in Infants With Retinopathy of Prematurity. Am J Ophthalmol. 2011

40. Shah PK, Narendran V, Tawansy KA, Raghuram A, Narendran K. Intravitreal bevacizumab (Avastin) for post laser anterior segment ischemia in aggressive posterior retinopathy of prematurity. Indian J Ophthalmol. 2007; 55(1):75-6. [PubMed: 17189897]

41. Kong L, Mintz-Hittner HA, Penland RL, Kretzer FL, Chevez-Barrios P. Intravitreous bevacizumab as anti-vascular endothelial growth factor therapy for retinopathy of prematurity: a morphologic study. Arch Ophthalmol. 2008; 126(8):1161-3. [PubMed: 18695118]

42. Mintz-Hittner HA, Kuffel RR Jr. Intravitreal injection of bevacizumab (avastin) for treatment of stage 3 retinopathy of prematurity in zone I or posterior zone II. Retina. 2008; 28(6):831-8. [PubMed: 18536599]

43. Weidemann A, Krohne TU, Aguilar E, et al. Astrocyte hypoxic response is essential for pathological but not developmental angiogenesis of the retina. Glia. 2010; 58(10):1177-85. [PubMed: 20544853]

44. Shalev B, Farr AK, Repka MX. Randomized comparison of diode laser photocoagulation versus cryotherapy for threshold retinopathy of prematurity: seven-year outcome. Am J Ophthalmol. 2001; 132(1):76-80. [PubMed: 11438057]

45. Cryotherapy for Retinopathy of Prematurity Cooperative Group. Multicenter trial of cryotherapy for retinopathy of prematurity: preliminary results. Pediatrics. 1988; 81(5):697-706. [PubMed: 2895910]

46. Tasman W. Ten-year follow-up from the CRYO-ROP study. Arch Ophthalmol. 2001; 119(8): 1200-1. [PubMed: 11483089]

47. Young TL, Anthony DC, Pierce E, Foley E, Smith LE. Histopathology and vascular endothelial growth factor in untreated and diode laser-treated retinopathy of prematurity. J AAPOS. 1997; 1(2):105-10. [PubMed: 10875087]

48. Stefansson E. The therapeutic effects of retinal laser treatment and vitrectomy. A theory based on oxygen and vascular physiology. Acta Ophthalmol Scand. 2001; 79(5):435-40. [PubMed: 11594975] 
49. Jaquet K, Krause K, Tawakol-Khodai M, Geidel S, Kuck KH. Erythropoietin and VEGF exhibit equal angiogenic potential. Microvascular research. 2002; 64(2):326-33. [PubMed: 12204656]

50. Ribatti D, Vacca A, Roccaro AM, Crivellato E, Presta M. Erythropoietin as an angiogenic factor. European journal of clinical investigation. 2003; 33(10):891-6. [PubMed: 14511361]

51. Chen J, Connor KM, Aderman CM, Smith LE. Erythropoietin deficiency decreases vascular stability in mice. J Clin Invest. 2008; 118(2):526-33. [PubMed: 18219389]

52. Smith SB, Duplantier J, Dun Y, et al. In vivo protection against retinal neurodegeneration by sigma receptor 1 ligand (+)-pentazocine. Invest Ophthalmol Vis Sci. 2008; 49(9):4154-61. [PubMed: 18469181]

53. Chen J, Smith LE. A double-edged sword: erythropoietin eyed in retinopathy of prematurity. J AAPOS. 2008; 12(3):221-2. [PubMed: 18396079]

54. Manzoni P, Maestri A, Gomirato G, Takagi H, Watanabe D, Matsui S. Erythropoietin as a retinal angiogenic factor. N Engl J Med. 2005; 353(20):2190-1. author reply -1. [PubMed: 16291990]

55. Chen J, Connor KM, Aderman CM, Willett KL, Aspegren OP, Smith LE. Suppression of retinal neovascularization by erythropoietin siRNA in a mouse model of proliferative retinopathy. Invest Ophthalmol Vis Sci. 2009; 50(3):1329-35. [PubMed: 18952918]

56. Suk KK, Dunbar JA, Liu A, et al. Human recombinant erythropoietin and the incidence of retinopathy of prematurity: a multiple regression model. J AAPOS. 2008; 12(3):233-8. [PubMed: 18589385]

57. Aher SM, Ohlsson A. Early versus late erythropoietin for preventing red blood cell transfusion in preterm and/or low birth weight infants. Cochrane Database Syst Rev. 2006; (3):CD004865. [PubMed: 16856063]

58. Gyllensten LJ, Hellstrom BE. Experimental approach to the pathogenesis of retrolental fibroplasia. I. Changes of the eye induced by exposure of newborn mice to concentrated oxygen. Acta Paediatr Suppl. 1954; 43(100):131-48. [PubMed: 13228020]

59. Smith LE, Kopchick JJ, Chen W, et al. Essential role of growth hormone in ischemia-induced retinal neovascularization. Science. 1997; 276(5319):1706-9. [PubMed: 9180082]

60. Hellstrom A, Perruzzi C, Ju M, et al. Low IGF-I suppresses VEGF-survival signaling in retinal endothelial cells: direct correlation with clinical retinopathy of prematurity. Proc Natl Acad Sci U S A. 2001; 98(10):5804-8. [PubMed: 11331770]

61. Langford K, Nicolaides K, Miell JP. Maternal and fetal insulin-like growth factors and their binding proteins in the second and third trimesters of human pregnancy. Hum Reprod. 1998; 13 (5):1389-93. [PubMed: 9647578]

62. Ong KK, Langkamp M, Ranke MB, et al. Insulin-like growth factor I concentrations in infancy predict differential gains in body length and adiposity: the Cambridge Baby Growth Study. Am J Clin Nutr. 2009; 90(1):156-61. [PubMed: 19474142]

63. Fowden AL. The insulin-like growth factors and feto-placental growth. Placenta. 2003; 24 (8-9): 803-12. [PubMed: 13129676]

64. Lutty GA, Chan-Ling T, Phelps DL, et al. Proceedings of the Third International Symposium on Retinopathy of Prematurity: an update on ROP from the lab to the nursery (November 2003, Anaheim, California). Mol Vis. 2006; 12:532-80. [PubMed: 16735995]

65. Lineham JD, Smith RM, Dahlenburg GW, et al. Circulating insulin-like growth factor I levels in newborn premature and full-term infants followed longitudinally. Early Hum Dev. 1986; 13 (1): 37-46. [PubMed: 3956421]

66. Hellstrom A, Carlsson B, Niklasson A, et al. IGF-I is critical for normal vascularization of the human retina. J Clin Endocrinol Metab. 2002; 87(7):3413-6. [PubMed: 12107259]

67. Stahl A, Chen J, Sapieha P, et al. Postnatal weight gain modifies severity and functional outcome of oxygen-induced proliferative retinopathy. Am J Pathol. 2010; 177(6):2715-23. [PubMed: 21056995]

68. Smith LE, Shen W, Perruzzi C, et al. Regulation of vascular endothelial growth factor-dependent retinal neovascularization by insulin-like growth factor-1 receptor. Nat Med. 1999; 5 (12):1390-5. [PubMed: 10581081] 
69. Lofqvist C, Chen J, Connor KM, et al. IGFBP3 suppresses retinopathy through suppression of oxygen-induced vessel loss and promotion of vascular regrowth. Proc Natl Acad Sci U S A. 2007; 104(25):10589-94. [PubMed: 17567756]

70. Wu C, Vanderveen DK, Hellstrom A, Lofqvist C, Smith LE. Longitudinal postnatal weight measurements for the prediction of retinopathy of prematurity. Arch Ophthalmol. 2010; 128(4): 443-7. [PubMed: 20385939]

71. Hard AL, Lofqvist C, Fortes Filho JB, Procianoy RS, Smith L, Hellstrom A. Predicting proliferative retinopathy in a Brazilian population of preterm infants with the screening algorithm WINROP. Arch Ophthalmol. 2010; 128(11):1432-6. [PubMed: 21060045]

72. Fluckiger S, Bucher HU, Hellstrom A, Lovqist C, Sturm V, Arri SJ. The early postnatal weight gain as a predictor of retinopathy of prematurity. Klin Monbl Augenheilkd. 2011; 228(4):306-10. [PubMed: 21484635]

73. Wu C, Lofqvist C, Smith LE, Vanderveen DK, Hellstrom A. Importance of Early Postnatal Weight Gain for Normal Retinal Angiogenesis in Very Preterm Infants: A Multicenter Study Analyzing Weight Velocity Deviations for the Prediction of Retinopathy of Prematurity. Arch Ophthalmol. 2012

74. Zepeda-Romero LC, Hard AL, Gomez-Ruiz LM, et al. Prediction of retinopathy of prematurity using the screening algorithm WINROP in a Mexican population of preterm infants. Arch Ophthalmol. 2012; 130(6):720-3. [PubMed: 22801831]

75. Vanhaesebrouck S, Daniels H, Moons L, Vanhole C, Carmeliet P, De Zegher F. Oxygen-induced retinopathy in mice: amplification by neonatal IGF-I deficit and attenuation by IGF-I administration. Pediatr Res. 2009; 65(3):307-10. [PubMed: 19092722]

76. Binenbaum G, Ying GS, Quinn GE, et al. A clinical prediction model to stratify retinopathy of prematurity risk using postnatal weight gain. Pediatrics. 2011; 127(3):e607-14. [PubMed: 21321036]

77. Eckert GU, Fortes Filho JB, Maia M, Procianoy RS. A predictive score for retinopathy of prematurity in very low birth weight preterm infants. Eye (Lond). 2011

78. Connor KM, SanGiovanni JP, Lofqvist C, et al. Increased dietary intake of omega-3polyunsaturated fatty acids reduces pathological retinal angiogenesis. Nat Med. 2007; 13(7):86873. [PubMed: 17589522]

79. Sapieha P, Stahl A, Chen J, et al. 5-Lipoxygenase Metabolite 4-HDHA Is a Mediator of the Antiangiogenic Effect of \{omega\}-3 Polyunsaturated Fatty Acids. Sci Transl Med. 2011; 3(69): 69ra12. 


\section{Key points}

1. Review the molecular pathogenesis of retinopathy of prematurity (ROP).

2. Understand the role of the hypoxia-induced growth factors, particularly vascular endothelial growth factor (VEGF), in the normal development of the retinal vasculature.

3. Understand the contribution of factors lacking after preterm birth; nutrition, insulin-like growth factor 1 (IGF-I) and polyunsaturated fatty acids (PUFAs), in normal retinal development.

4. Describe clinical applications for the prevention/treatment of ROP, which have emerged from molecular studies.

5. Appreciate the importance of neonatal weight gain as a predictor for the development of ROP. 
A In Utero:

Normal vessel growth

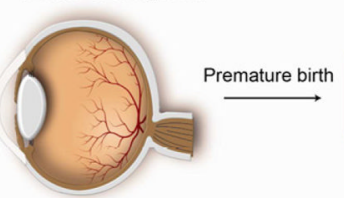

B Phase I:

Vessel growth stops
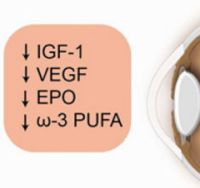
Early Treatment
Prevention of Phase I

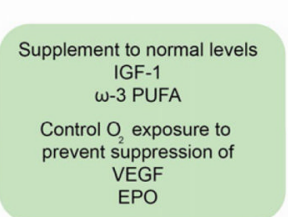

C Phase II:

Retinal neovascularization

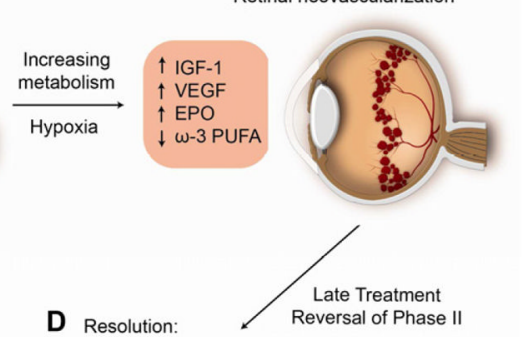

D Resolution: Reversal of Phase

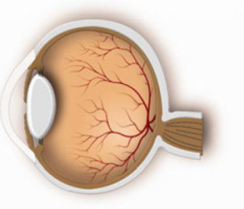
Inhibit
VEGF

Figure 1. Treatment of ROP is based on understanding pathogenesis

1. Laser photocoagulation of ROP: Hypoxic retina anterior to neovascularization in phase II of ROP which produces VEGF and Epo is destroyed to decrease pathological blood vessel formation (promoting $\mathrm{C}$ to $\mathrm{D}$ )

2. Anti-VEGF therapy: Direct suppression of neovascularization with suppression of VEGF (promoting $\mathrm{C}$ to $\mathrm{D}$ )

3. Increasing IGF-1 to in utero levels after birth: prevents vessel loss (phase I) (preventing A to B) to prevent phase II (C)

4. Control of oxygen after preterm birth: Prevents hyperoxia induced suppression of Hif regulated factors VEGF and Erythropoietin that are necessary for normal retinal vascular development thus preventing vessel loss (preventing A to B)

5. Maintaining adequate intake of the essential fatty acid DHA after preterm birth: Promotes normal vascularization and directly inhibits neovascularization (promote B to D and $\mathrm{C}$ to $\mathrm{D})$

6. Monitoring postnatal growth which is based on rate of increase of postnatal IGF-1 levels: Predicts the future development of neovascular ROP (C) 


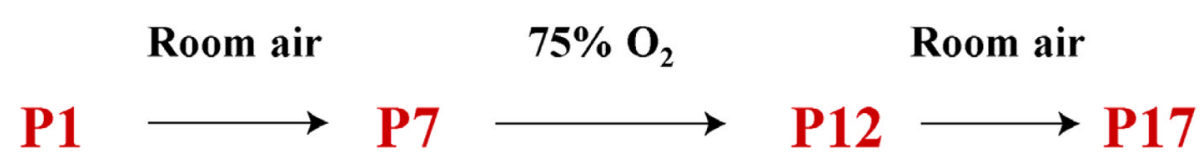

\begin{tabular}{|l|l|l|}
\hline Normal Development & Vessel Loss & Regrowth / NV \\
\hline
\end{tabular}

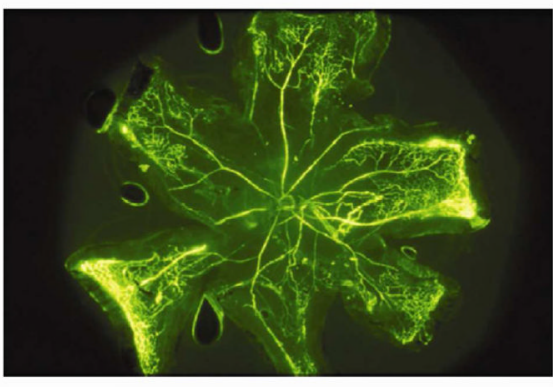

P8 Hyperoxia

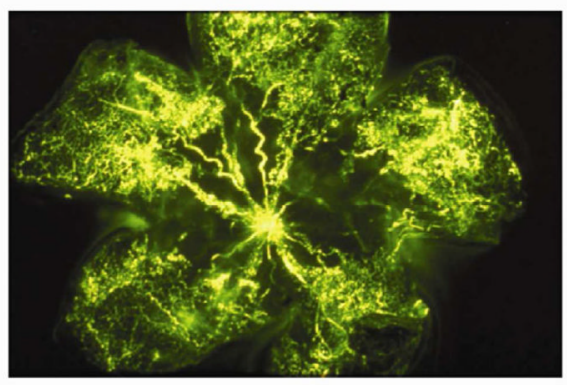

P17 Hyperoxia

Figure 2. Mouse model of oxygen-induced retinopathy

Neonatal mice are exposed to $75 \%$ oxygen from postnatal day 7 (P7) until P12 causing vessel loss and cessation of vascular growth to simulate Phase I of ROP. The central retinal microvessels are obliterated and radial vascular growth ceases. When the mice are returned to room air with incompletely vascularized retina, retinal neovascularization is seen, similar to phase II of ROP. Vessel proliferation is maximum at P17 then regresses, which also occurs in human ROP. These changes can be quantified in retinal flat mounts. 